\title{
Entrevista com Pedro Garcez Ghirardi, tradutor de Orlando Furioso
}

Dirceu Villa e Afonso Teixeira Filho

O poema de Ludovico Ariosto (1474-1533) é mais do que um poema épico, levando o herói, retirado do ciclo carolíngeo, dos campos de batalha ao refúgio na loucura. A intenção de Ariosto era continuar o Orlando Innamorato, de Boiardo, mas foi além disso: em seu poema, a razão de ser do guerreiro, a guerra, dá lugar à paixão por Angélica, uma paixão que se transforma em loucura. O Orlando furioso é um herói que, em plena época da razão, faz da loucura a sua razão de ser, e parte em desvairadas aventuras que, de certa forma, nos lembram o Dom Quixote. O poema de Ariosto fala de castelos construídos no topo do mundo, de reinos exóticos e de uma viagem à lua onde ficavam guardados os juízos perdidos.

Pode parecer estranho que, em plena época da Renascença, alguém tenha escrito um poema assim. Mas a época é tanto uma época da razão quanto de seu oposto. Porque tudo isto, razão, paixão e loucura são coisas humanas. $\bigcirc$ poema, pelo fato de ser estranho talvez, ganhou o coração dos gênios: Camões, Cervantes, Voltaire. Quando Cervantes escreveu o Quixote, já conhecia uma tradução do Orlando furioso para o castelhano. Mas se Camões, poucos anos depois de Ariosto, já apresentava 
em Os Lusíadas influências do Furioso, o português só viria a conhecer bem mais tarde uma tradução do poema italiano e, mesmo assim, em prosa.

No Brasil, chega-nos só agora uma tradução desse poema. O professor Pedro Garcez Ghirardi, da Universidade de São Paulo, lançou em 2002 a primeira parte do poema, traduzido em versos e obedecendo o mesmo esquema rítmico do original. $\bigcirc$ livro foi publicado pela Ateliê Editorial e contém os oito primeiros cantos do poema e mais 12 episódios dos cantos seguintes.

Os Cadernos de Literatura em Tradução entrevistaram, para este número o professor que, pelo seu trabalho, ganhou o Prêmio Jabuti de 2003 na categoria tradução.

CLT: Para começar, duas perguntas em uma: por que o Orlando Furioso? E por quê, na sua opinião, um poema dessa importância só agora começa a ser traduzido integralmente em versos para o português?

PGG: $O$ poema de Ariosto ficou quase esquecido no mundo contemporâneo de língua portuguesa, apesar de algumas tentativas de divulgação. Mas é preciso observar que mesmo outros grandes poetas italianos mais lembrados, como Dante, só tiveram traduções portuguesas em verso a partir do século XIX.

CLT: Há uma tradução antiga, em prosa, feita em Portugal se eu não me engano. $\bigcirc$ que você pensa dela?

PGG: A tradução portuguesa em prosa foi feita por Xavier da Cunha, em fins do século XIX, e está baseada na tradução francesa, também em prosa. É um trabalho que teve o mérito de divulgar o Orlando Furioso em nossa língua, mas que tem os limites de toda a prosificação de texto poético.

CLT: Como foi (e está sendo) o processo de tradução? Você parte do verso a verso ou começa numa avaliação da(s) estrofe(s) para daí ir à tradução de cada verso em particular? 
PGG: A tradução deste poema, desde o início, me tem trazido grande satisfação. Mas, como se pode imaginar, é um processo demoradíssimo. Em geral, tomo como base a estrofe, a famosa oitava de Ariosto, que, como observam os críticos, é muitas vezes uma pequena obra-prima em si mesma.

CLT: a. Na introdução você comenta de maneira breve as relações poéticas - principalmente no caso da oitava - entre Camões e Ariosto. Você considerou a oitava camoniana no sentido de aproveitar soluções, por exemplo, sintáticas para a transposição do italiano para o português?

b. A escolha do verso feita por Camões para compor Os lusíadas parece indicar que ele pretendia imitar o verso endecassilábico de Ariosto. Nós comprovamos isso quando vemos que Camões usou apenas rimas paroxítonas em sua epopéia. Você acredita que Camões teve mesmo essa intenção?

PGG: Sobre as relações entre Camões e Ariosto muito tem sido escrito, desde o clássico estudo de José Maria Rodrigues (As Fontes d'Os Lusíadas). Como se sabe, Camões, já nas primeiras estrofes de seu poema evoca os heróis de Ariosto, mas parece estabelecer com o Orlando Furioso uma relação ao mesmo tempo de aproximação (no plano expressivo) e de afastamento (no plano da liberdade fantástica). Isso se explica se lembrarmos que - Orlando Furioso aparece em 1516 (a edição definitiva é de 1532), ainda no início do Renascimento, portanto. E aparece como afirmação da autonomia do poético (como o Príncipe de Maquiavel, no mesmo período, afirma a autonomia do político). Entretanto, com o refluxo da segunda metade do século XVI (basta aqui lembrar a reforma tridentina e a cristalização de uma retórica normativa), a fantasia poética se vê mais vigiada pela ortodoxia religiosa e retórica. Daí a complexa relação entre um grande poeta do pleno Renascimento, como Ariosto, e grandes poetas do fim do Renascimento, como Camões e Tasso. É uma relação que discuto brevemente no estudo introdutório de minha tradução. De 
qualquer forma, em meu trabalho de tradutor, procurei ter sempre em vista as lições camonianas que, aliás, cito mais de uma vez em minhas notas.

CLT: Houve alguma preocupação especial quando traduziu versos particularmente famosos?

PGG: O Orlando Furioso é rico em trechos merecidamente famosos, como o da 'Viagem à Lua' ou o do 'Castelo Encantado', ou o da descrição da beleza de Alcina (para citar só alguns). Mas traduzir Ariosto é estar sempre muito atento, pois, como dizia um de seus primeiros leitores, Maquiavel, 'il poema è bello tutto' e isto redobra a responsabilidade do tradutor.

CLT: Qual você diria que foi a maior dificuldade encontrada na tradução do poema?

PGG: Dificuldades não faltam. Uma delas é conseguir reproduzir a leveza do 'sorriso ariostesco', que cria prodígios no plano expressivo sem aparentar esforço. A oitava de Ariosto, a ottava d'oro, com toda a sua musicalidade, ironia, refinamento e, ao mesmo tempo, com seu tom coloquial, é, a meu ver, um dos maiores desafio do tradutor.

CLT: Como você situaria o Orlando Furioso dentro da literatura fantástica?

PGG: O poema de Ariosto está ao mesmo tempo próximo e distante da atual literatura fantástica. Próximo, pela exuberância mesma da fantasia e pelas intervenções do maravilhoso. Distante, porque, como se sabe, o fantástico atual nasce, a partir do século $X V I I I$, como reação ao racionalismo dominante. $O$ fantástico de hoje corresponde a tempos em que a loucura é marginalizada, como bem observa Foucault. No Renascimento, pelo contrário, a loucura ainda é tema central (não só em Ariosto, mas em Erasmo e, mais tarde em Cervantes). No Orlando Furioso loucura e razão são inseparáveis, como tento esclarecer em minha introdução citada. A coexistência de razão e loucura é precisamente o cerne 
das oitavas, onde o fantástico mais surpreendente se expressa em versos magistralmente equilibrados. Note-se, também, que, ao contrário da maioria dos autores fantásticos de hoje, Ariosto parte do imaginário popular. As histórias de Carlos Magno e Roldão sobrevivem até mesmo na literatura de cordel. Esse caráter popular do poema foi o que bem notou, entre nós, Araripe Jr. (e, digase de passagem, muito antes que Bakhtin notasse o mesmo em Rabelais). A fantasia de Ariosto se alimenta do filão popular do Renascimento, que só hoje começa a ser valorizado (bem por isso - Orlando Furioso conheceu popularidade surpreendente em seu tempo).

CLT: Italo Calvino afirmou, em A Estrutura do "Orlando" que o jogo de Ariosto era "o jogo de uma sociedade que se sente produtora e depositária de uma visão de mundo, mas sente também o vazio que se cria sob seus pés, entre ruídos de terremoto". Você concorda que o poema implique esse aspecto, digamos, emblemático?

PGG: A propósito de terremoto, lembremos as ruínas dos grandes impérios, descritas por Ariosto no episódio da 'Viagem à Lua'. O Orlando Furioso assinala o 'terremoto' da passagem de uma cultura onde predominam as certezas e o sagrado (o Orlando da tradição anterior é um paladino da fé) para uma cultura profana, onde a dúvida ganha espaço. "Guarda il giudizio uman come spesso erra" dirá Ariosto. E o contraste entre aparência e realidade permeia todo o poema. Basta lembrar o belíssimo episódio do Castelo Encantado, celebrado por Borges com estes versos: "el singular castillo en el que todo / es (como en esta vida) una falsía".

CLT: A loucura de Orlando e sua paixão enlouquecida por Angélica terá alguma influência no Quixote?

PGG: O Orlando Furioso é várias vezes citado no Dom Quixote e a presença de Ariosto em Cervantes é bem conhecida e estudada. Mas, para além das semelhanças, há entre os dois escritores uma importante diferença, pouco lembrada: em Ariosto, 
não é somente o protagonista, Orlando, que enlouquece, é o próprio poeta que ao longo do texto vai anunciando sua loucura, desde as primeiras estrofes do poema. Ariosto, como Orlando, enlouquece por amor. É um louco por amor que conta a história de outro louco por amor. Nisto está a chave do 'sorriso ariostesco', da ironia do poema.

CLT: A mulher apresentada nessa epopéia, sobretudo a própria Angélica, é uma mulher idealizada, retirada dos romances de cavalarias do ciclo arturiano, ou é uma mulher mais real, idealizada dentro da concepção renascentista da realidade?

PGG: No centro do poema de Ariosto está a mulher, Angélica, que toma nas mãos seu próprio destino (foge do campo cristão, foge dos seus pretendentes, para voltar à sua terra e escolher seu próprio amor). Outras grandes figuras femininas (Genebra e, sobretudo, Olímpia, a mulher dividida entre o amor e o poder) tornaram-se famosas nesse poema que, como testemunha Montaigne, era cantado pelas camponesas italianas do século XVI. Mas em Ariosto a mulher, como o homem, é feita de razão e loucura. E um episódio como o da 'Taça dos Maridos Traídos' mostra que o poema evita uma visão idealizada, hagiográfica, de qualquer dos sexos.

CLT: Como você considera o tipo de tradução que faz em relação às discussões sobre tradução poética no Brasil?

PGG: As discussões teóricas são sempre proveitosas e eu mesmo tenho considerado questões teóricas nos cursos de tradução que ministro. Mas a prática tradutória, a meu ver, é uma experiência em certos aspectos irredutível a quaisquer teorizações.

CLT: Enquanto você se preparava para lançar a sua tradução de Ariosto, várias traduções importantes estavam sendo feitas no Brasil, como a llíada de Homero, por Haroldo de Campos, $\bigcirc$ idiota, de Dostoievski, por Paulo Bezerra, o Finnegans Wake, de Joyce, por Donaldo Schüler. Há muito tempo não se falava de 
Ariosto no Brasil. O fato de a sua tradução, que concorreu com a segunda parte da llíada, ter recebido o prêmio Jabuti, foi uma surpresa para você?

PGG: Como já disse em outra ocasião, ter concorrido ao "Jabuti", e mais ainda ao lado de Haroldo de Campos, já foi, por si só, um prêmio.

CLT: Quando podemos esperar mais do Orlando Furioso?

PGG: Ars longa, vita brevis, dizia-se. E a vida fica ainda mais breve com o acúmulo dos compromissos profissionais e pessoais que parecem consumir todo o nosso tempo. Mas continuo a trabalhar e espero ainda oferecer ao público brasileiro ao menos alguns cantos mais do poema. 
LivRaria Humanitas

Av. Prof. Luciano Gualberto, 315

Cid. Universitária

05508-900 - São Paulo - SP - Brasil

Tel: 3091-3728 / 3091-3796

e-mail: livrariahumanitas@usp.br
HUMANITAS - DISTRIBUIÇÃO

Rua do Lago, 717 - Cid. Universitária 05508-900 - São Paulo - SP - Brasil

Telefax: 3091-4589/1514

e-mail:pubfflch@edu.usp.br

http://www.fflch.usp.br/humanitas

FICHA TÉCNICA

Mancha $11,5 \times 19 \mathrm{~cm}$

Formato $16 \times 22 \mathrm{~cm}$

Tipologia Futura Lt BT

Papel miolo: Off set $75 \mathrm{~g} / \mathrm{m}^{2}$

capa: Cartão branco $180 \mathrm{~g} / \mathrm{m}^{2}$

Impressão e acabamento GRÁFICA DA FFLCH

Número de páginas 188

Tiragem 200 exemplares 